\title{
Conduct disorder
}

\section{Conduct disorders and us: from heart sink to heart warming?}

\section{Daphne V Keen}

\section{The "Child in Mind" initiative and the appointment of a new specialist consultant in child mental health offer hope for the future}

$\mathrm{T}$ he recent NICE guidance on conduct disorders $(\mathrm{CDs})^{1}$ places paediatricians centre stage in the assessment process. With behavioural disorders contributing to $25-30 \%$ of some paediatricians' caseloads, ${ }^{2}$ it is very gratifying to see our role appropriately recognised. This is not always the case. Both here and abroad, paediatricians complain that, despite being an integral part of child mental health service provision, at a national level we often seem invisible. ${ }^{3}$

Now, for a question: which clinical conditions are your most difficult? Paediatricians, probably universally, most often cite CDs. ${ }^{4}$ A UK survey of trainees' child mental health training requirements, conducted in 2006, sent back a very strong message of feeling underprepared, and over $90 \%$ of respondents said they needed more training, particularly in behavioural disorders (M Davie, personal communication), a perception also shared by recently appointed consultants. ${ }^{5}$

A resolution to this problem will hopefully flow from two major College initiatives: the "Child in Mind" educational modules for the first years of specialist training, and the appointment of a new specialist consultant in child mental health.

So, in this context how should paediatricians work with CDs?

\section{WHAT IS CONDUCT DISORDER?}

$\mathrm{CD}$, the most common problem referred to child and adolescent mental health services (CAMHS), ${ }^{6}$ is defined by ICD- 10 and DSM-IV criteria as a persistent pattern of behaviour in which the basic rights of others, or major societal rules, are violated. $C D$, at the extreme end of the spectrum, is one of a triad of closely related and overlapping patterns of difficult and challenging behaviour known as disruptive behaviour disorders (DBD) which includes attention deficit hyperactivity disorder (ADHD) and oppositional defiant disorder (ODD). ODD is a milder pattern of negativity, defiance and disobedience commonly presenting as early as 3 years of age and almost always preceding $\mathrm{CD}$; $\mathrm{CD}$ is more severe and includes social aggression and destruction or theft of property. In practice many authors use the term "CDs" to describe both CD and ODD.

The prevalence of CD at 5-10 year olds is $7 \%$ in boys and $3 \%$ in girls, and at adolescence $8 \%$ and $5 \%$, respectively. Longitudinal studies suggest the "orderly unfolding of DBD symptoms with age". Over $60 \%$ of 3 year olds with untreated CDs still exhibit problems at 8 years of age $^{1}$ and early patterns are remarkably stable, with just under half of affected 810 year olds remaining antisocial at 18 years of age. ${ }^{8}$ Children who become violent as adolescents can be identified with almost $50 \%$ reliability as early as 7 years of age. ${ }^{6}$

The impact on quality of life for the child and their carers is great. Prognosis for adult life is poor. Approximately 50\% will receive a diagnosis of antisocial personality disorder, with others being diagnosed with a range of serious psychiatric disorders such as schizophrenia and major depressive disorder. ${ }^{1}$ Nonpsychiatric antisocial behaviours include theft, violence, drink driving and use of illegal drugs. The social costs are considerable. CD is associated with incomplete schooling, unemployment and financial dependency, poor interpersonal relationships and abuse of the next generation of children. ${ }^{8}$ The estimated financial cost is $£ 15270$ per untreated child per annum. ${ }^{6}$

\section{AETIOLOGICAL FACTORS}

The developmental pathways of antisocial behaviour indicate two aetiological types with early and adolescent onset. Early onset $\mathrm{CD}(<10$ years) has its origins in biological factors affecting temperament and physiological responses, and in neurodevelopmental processes affecting cognitive function. In contrast, adolescent onset has its origins predominantly in social processes.

Prenatal factors (eg, maternal smoking, substance abuse) and perinatal complications to some extent predict CD. ${ }^{67}$
Co-occurring ADHD is a crucial factor. Present in over $25 \%$ of children with $\mathrm{CD}^{9}$ and contributing to a greatly increased risk of behavioural and mental health problems in adolescence, ${ }^{8}$ its role in the development of CD is controversial, and possibly mediated by coexisting ODD, with ADHD per se causing earlier onset of $\mathrm{CD} .{ }^{10} \mathrm{ADHD}$ probably accounts for the very considerable increased risk for all DBDs seen in Tourette syndrome. ${ }^{11}$

Having a chronic health disorder is associated with a three-fold increased risk of behavioural disorder. Conduct problems and hyperactivity seem frequently associated with sleep disorders (eg, sleepdisordered breathing and restless leg syndrome) and may remit with treatment. ${ }^{12}$ In disorders affecting the central nervous system (including epilepsy), the risk factor for $\mathrm{CD}$ increases to approximately five-fold ${ }^{6}$ with particular risk in hemiplegia (34\% CD) and in intellectual disability (25\% CD)..$^{13}$ Cognitive impairments in $\mathrm{CD}$ are particularly evident in reading skills with severely delayed levels seen in a third of patients. ${ }^{6}$

There has been considerable interest in the potential links between temperament and antisocial behaviour, CD and psychopathology. Temperament reflects an underlying biological reactivity affecting quality and intensity of mood expression, and adaptability to new situations. ${ }^{8}$ The development of CD has been linked to a low fear, low cortisol response possibly disrupting the formation of guilt and the development of concern about punishment, and inhibiting the development of empathy. ${ }^{14}$

Having a "difficult temperament" is associated with high rates of motherchild conflict. ${ }^{8}$ Despite the parent-child dynamic being a crucial area for the understanding of the development of cognition, language and social learning, it is still unclear how these factors interact and what is primary and what secondary.

For example, aspects of mother-child interaction and home environment can predict language skill at the age of 3 years. ${ }^{6}$ Maternal disciplinary strategies are a key influence upon the development of empathy and social cognition. Harsh parenting may impair developing theory of mind (TOM) skills. On the other hand, advanced TOM skills appear to buffer even children as young as 2 against the effects of harsh parenting. ${ }^{15}$ Children with CDs may display a deviant $\mathrm{TOM}^{15}$ and impaired processing of social information, for example, interpreting benign social cues as provocative. By being socially inept, such children tend to reduce the likelihood of potentially beneficial adult interaction. ${ }^{6}$ However, up to two thirds of 
Table 1 Child in Mind: grid for assessment of behaviour

\begin{tabular}{llllll}
\hline Factors to consider & Biological & PsychologicalSocial & Family & School & Friends \\
\hline Predisposing & & & \\
(vulnerability) & & & \\
Precipitating (triggers) & & & \\
Perpetuating & & \\
(maintaining) & & & \\
Protective (resilience) & & & \\
\hline
\end{tabular}

Provide a "safe space" that allows the parent to feel their concerns are heard and understood. Listen to the parent's narrative. Why this child, and why at this time?

children with CD show pragmatic language impairment with behavioural features similar in nature and degree to those of children with autism, ${ }^{16}$ which suggests, but not with any certainty, a neurobiological origin.

The considerable body of research into the medical correlates of CD (genetics, neuro-anatomy and physiology, and cognition) has tended to conclude that, particularly in the most severe and persistent forms of $\mathrm{CD}$, although intrinsic child factors provide the biological substrate, it is likely that learning experience can modify the biological systems that shape temperament, and social/environmental factors further interact to shape the ultimate behavioural profile. ${ }^{814}$

The relevant social and environmental factors encompass issues too vast and complex to do justice to here. However, of particular importance is the role of abusive and injurious parenting, thought to be the most influential risk factor, ${ }^{6}$ with the usual suspects of social and economic disadvantage, parental mental health and educational failure (whether from social or academic causes) being significant risk factors. Aspects of parentchild interaction particularly associated with antisocial behaviour are poor supervision, erratic harsh discipline, parental disharmony, rejection and criticism, low parental involvement in the child's activities, and an insecure or disorganised attachment pattern. ${ }^{16}$

Separating out the relative contributions of biological from environmental risk factors is a significant task that remains largely incomplete. ${ }^{7}$

\section{NOW ENTER THE PAEDIATRICIAN (AS DIRECTED, CENTRE STAGE)}

\author{
.... a diagnostic interview is only fruit- \\ ful if it is ... therapeutic... ${ }^{17}$
}

\section{CASE SCENARIO}

A GP refers 5-year-old child to a paediatrician. His mother thinks there must be something wrong with her son. He's completely different to his brothers; always extremely over-active, can't be disciplined, alarmingly aggressive at home and at school. School had referred to CAMHS with these concerns and his poor concentration and social relationships. The mother went once but won't go back as they focussed too much on her and not on her son who's the problem.

Often parents sense the biological underpinning of early onset CD as "something's not right with Jack", and seek a medical route. This sentiment can sometimes be construed incorrectly as parental hostility, negativity or seeking a "quick fix".

The traditional medical model has limitations in explaining and managing problems in human behaviour. In contrast, the bio-psycho-social (BPS) model of medicine, which developed out of psychoanalytic thinking in the 1960s, was seen by many as standing for the best in psychosocially sensitive clinical care. ${ }^{18}$ However, the BPS baby risked being thrown out with the water of psychoanalysis, with the latter's decline and the rise of the new biological psychiatry. It has been rescued with the

Table 2 Identifying neurobiological factors

\begin{tabular}{ll}
\hline Dimensions & Diagnostic categories \\
\hline Cognitive disabilities & Global and specific learning disability \\
Hyperactive-impulsive behaviour & ADHD \\
Dysmorphic features & Syndromes (eg, chromosomal, alcohol-related fetopathy) \\
Motor clumsiness & Developmental coordination disorder \\
Social learning & Autistic spectrum/Asperger syndrome \\
Language impairment & Semantic-pragmatic disorder \\
Motor and vocal tics & Tourette syndrome \\
Sleep disturbance & Sleep disorders \\
\hline
\end{tabular}

development of important new innovative models of practice, of which Child in Mind is a superb example, that integrate apparently disparate theoretical approaches, providing powerful tools for dealing with the complex multidimensional aspects of child behavioural disturbance.

\section{Setting the scene}

The paediatrician should

(1) allocate time for the appointment (at least $\mathrm{l} \mathrm{h}$ ), and

(2) obtain details from school on achievement and classroom and social behaviour (note: CD and ADHD may be missed without information about functioning in school $^{9}$ ) and other relevant background.

In the stage 2 modules (paediatric assessment of behaviour), the familiar medical model combines with the BPS model, family therapy techniques and social learning theory. Viewing behaviour as a form of communication that requires unravelling, it provides a framework for understanding the origins of behavioural disturbance and for developing a diagnostic formulation (table 1 ).

\section{Possible findings in the case}

Predisposing/precipitating/perpetuating factors in our hypothetical case include:

(a) biological: domestic violence likely during pregnancy, alcohol and tobacco consumption, growth retarded (birth weight $=2.2 \mathrm{~kg}$ ), developmental concerns (poor concentration, immature speech, motor clumsiness, hyperactive),

(b) psychological: postnatal depression, recurrent episodes of depression, and

(c) family: consistent discipline impossible, mother demoralised, father critical and violent if child cries.

Protective factors include:

(a) school-enlisted behavioural team (child improving and responding well), and

(b) sibling helping out when Mum is "down"; Mum's parents try to help (but kept at a distance by the father)

Research supports the dimensional conceptualisation of developmental disorders $^{21}$ and backs anecdotal experience that a sizeable proportion of the children we see with significant impairment have insufficient symptoms to meet criteria for one particular diagnostic category (table 2) 
Table 3 NICE recommendations for P-T/EPs interventions

P-T/EPs should have the following features

Be structured and informed by principles of social-learning theory

Include relationship-enhancing strategies

Have an optimum of $8-12$ sessions

Enable parents to identify their own parenting objectives

Incorporate role play as well as homework

Be delivered by appropriately trained and skilled facilitators in a productive therapeutic alliance with parents

Individual-based P-T/EPs only where there are particular difficulties or the situation is too complex

P-T/EP, parent training/education programme.

\section{Possible action}

Discuss suspected

(a) neurobiological factors,

(b) perpetuating factors that need to be addressed, and

(c) protective factors in school and family.

Encourage the mother to work out her own solutions with you and, for example:

(a) consider further developmental assessments and treatment,

(b) discuss protective factors in the social environment that could be enlisted urgently, for example, refuge from violence, social service support, and

(c) set the scene for referral on to parenting groups or other mental health intervention.

One should not become consumed with agonising about on which side a child falls of what are increasingly seen as rather poorly defined diagnostic cut-off points, but should focus on interventions to ameliorate obvious impairments. This may cause some clinical discomfort and uncertainty, but combining dimensional and categorical approaches, rather than diagnostic status, seems the most useful way to understand and identify those in need of intervention. ${ }^{913} 19$ However, as resources often only follow from a diagnostic label, pragmatic approaches to diagnostic categorisation are unavoidable. The main point is that each identified area of impairment should receive appropriate intervention in its own right.

\section{FURTHER INTERVENTIONS FOR CD Psychosocial}

In the past 10-15 years, there has been a dramatic increase in randomised controlled trials which suggest a range of school and family programmes that have the potential to reduce levels of childhood conduct problems. ${ }^{20}$ However, despite certain overall school characteristics being protective and promoting resilience, remediation programmes for academic underachievement do not appear to reduce antisocial behaviours. ${ }^{6}$ The most effective interventions appear to be psycho-social focussing on multiple domains, enhancing protective as well as reducing risk factors. ${ }^{7}$

This is reflected in the NICE guidance ${ }^{1}$ that concludes that for younger children (developmental or chronological age up to 12 years) group-based parent training/ education programmes (P-T/EPs) such as the Webster Stratton Incredible Years programme and the Triple P-Positive Parenting Programme, are the most successful and cost effective (table 3 ).

For adolescents, the situation is more complex and research findings give mixed results. Even the most successful programmes achieve modest results and at present we know little about whether effects are sustained over time. ${ }^{8}$

\section{Psychopharmacology}

There is a overall view among clinicians that psychotropic medication has an

Table 4 Interventions for DBDs

Suggested process for management

Points of liaison with CAMHS dependent on local service arrangements

Ensure medication, where indicated for underlying medical conditions (eg, ADHD, Tourette syndrome, epilepsy), is optimal

Offer basic behavioural management (eg, Child in Mind)

Engage clinical and educational interventions for language and social cognition deficits and educational support for cognitive deficits

Engage social and voluntary agencies for family support

If established CD, support family towards a referral for a P-T/EP

If established CD+severe persistent aggression/impulsiveness despite P-T/EP, or P-T/EP not suitable, discuss benefits of adding pharmacotherapy important role in severe disorders, "often offering the hope of symptomatic relief in conditions hitherto regarded as un-treatable", and although many child and adolescent psychiatrists and paediatricians feel relatively unskilled, they are increasingly using psychopharmacology, particularly in ADHD and autism. ${ }^{21} 22$

International consensus recommends psychosocial intervention as first line treatment for primary $\mathrm{CD}$. When associated with ADHD, this should be combined with pharmacotherapy. When aggression/impulsivity is marked and persistent, pharmacotherapy should be considered as an "add on". ${ }^{23}$

Psychostimulants have a substantial effect size on aggression in $\mathrm{ADHD}^{24}$ and clonidine can reduce the severity of conduct symptoms. ${ }^{25}$ Mood stabilisers and beta-blockers may also have a role in aggression, but increasingly evident is the efficacy of atypical antipsychotics (in particular risperidone) in the treatment of aggression in selected paediatric populations. ${ }^{26}$ Such pharmacology requires careful titration and regular long-term followup. ${ }^{23}$

\section{TOWARDS A COMPREHENSIVE PAEDIATRIC MENTAL HEALTH PROVISION}

While paediatricians are able to offer a considerable amount of expertise (table 4), there is clear need for related high quality services to follow on seamlessly from paediatric assessment and management. This unfortunately continues to present us with major challenges. Sadly (and incredibly), many of us cannot access appropriate integrated multidisciplinary assessment; we despair at bureaucratic barriers and separation of services, and sometimes, in the absence of alternatives, at having to do complex mental health work with inadequate support or training.

On the other hand, there are increasingly examples of excellent mental health teams working cooperatively between paediatrics and CAMHS, with the latter even funding paediatric time. A 2004 "straw poll" of paediatricians (C Ni Bhrolchain, personal communication) found that about $50 \%$ had active clinical or educational collaboration with their CAMHS team and $10 \%$ were a resource working within CAMHS to provide consultation on paediatric aspects of care. Clearly, for early onset $C D$ we have potential to greatly enhance care at the assessment stage. The signs are that these innovative models facilitate a new approach to holistic health care that families find less stigmatising and more approachable. 
The National Service Framework for Children, Young People and Maternity Services ${ }^{27}$ makes explicit recommendation for mental health to be a core component of paediatric training. Child in Mind has laid the foundations and the feedback from the pilot sites shows greatly increased confidence in assessing and managing general behavioural problems. Hopefully, Child in Mind will come to be considered a core component of every paediatrician's training. However, if we are to fulfil NICE's expectations in the area of complex CDs, mental health training needs to be extended into post-membership level. It will be imperative to quickly establish the specialist training pathway for a consultant in child mental health who will provide leadership, expertise and educational supervision and address the need for other levels of postgraduate continuing professional development. This will necessitate increased collaboration with CAMHS teams for training and support, which hopefully will lead to greater shared understanding and provide a firmer foundation for working relationships to deliver better and more integrated mental health care to young people and their families.

There is reason to be optimistic about the future.

\section{ACKNOWLEDGEMENTS}

I am very grateful to Paul Carter, Val Harpin, Geoff Kewley, Neil Simpson and Avril Washington who willingly shared their thoughts about the paediatrician's role in conduct disorder.

\section{Arch Dis Child 2007;92:838-841.}

doi: 10.1136/adc.2006.106369

Correspondence to: Daphne V Keen, Room 2.35, Clare House, St George's Healthcare NHS Trust, Blackshaw Road, London SW17 OQT, UK; daphne.keen@stgeorges.nhs.uk
Accepted 10 May 2007

Competing interests: None.

\section{REFERENCES}

1 NICE. Conduct disorder in children - parenttraining/education programmes, Technology appraisal guidance 102. London: National Institute for Health and Clinical Excellence, July, 2006.

2 Rahman F, Adamson L, Spencer N, et al. Do community paediatricians contribute to a comprehensive CAMHS service? Arch Dis Child 2006;91(Suppl 1):A39.

3 Coté-Boileau T. On reading a government document: when will we finally achieve the true organisation of paediatric care in Quebec? Paediatr Child Health 2005; 10:443-4

4 Couper RTL, Henry RL, South M. Paediatrics: tackling the common problems. Med J Aust 2004; 181:505-6.

5 Graham P. Mental health must be "centre stage" in child welfare. Arch Dis Child 2000;83:4-7.

6 Richardson J, Joughin C. Parent-training programmes for the management of young children with conduct disorder: findings from research. London: Royal College of Psychiatrists, 2002.

7 Burke JD, Loeber R, Birhamer B. Oppositional defiant disorder and conduct disorder: a review of the past 10 years, part II. J Am Acad Child Adolesc Psychiatry 2002;40:1275-93.

8 Liabo K, Richardson J. Conduct disorder and offending behaviour in young people: findings from research. London: Jessica Kingsley Publishers, 2007.

9 Ford T, Goodman R, Meltzer H. The British Child and Adolescent Mental Health Survey 1999: the prevalence of DSM-IV disorders. J Am Acad Child Adolesc Psychiatry 2003;42:1203-11

10 Loeber R, Burke JD, Lahey BB , et al. Oppositional defiant disorder and conduct disorder: a review of the past 10 years, part I. J Am Acad Child Adolesc Psychiatry 2000;39:1468-83.

11 Sukhodolsky DG, Scahill L, Zhang H, et al. Disruptive behaviour in children with Tourette's syndrome: association with ADHD comorbidity, tic severity, and functional impairment. J Am Acad Child Adolesc Psychiatry 2003;42:98-104.

12 Chervin RD, Dillon JE, Archbold KH, et al. Conduct problems and symptoms of sleep disorders in children. J Am Acad Child Adolesc Psychiatry 2002;42:201-8.

13 Baird G, Santosh PJ. Interface between neurology and psychiatry in childhood. J Neurol Neurosurg Psychiatry 2003;74:1-11

14 Nigg JT. Temperament and developmental psychopathology. J Child Psychol Psychiatry 2006; $47: 395-422$
15 Hughes C, Ensor R. Behavioural problems in two-year-olds: links with individual differences in theory of mind, executive function and harsh parenting. J Child Psychol Psychiatry 2006:47:488-97.

16 Gilmour J, Hill D, Place $M$, et al. Social communication deficits in conduct disorder: a clinical and community survey. J Child Psychol Psychiatry 2004:45:967-78.

17 Winnicott DW. Through paediatrics to psychoanalysis. Collected papers. London: Karnac Books, 1987.

18 Brown T. The growth of George Engel's biopsychosocial model. Corner Society presentation, 24 May 2000. http://www.humannature.com/free-associations/engel $1 . \mathrm{html}$ (accessed 12 June 2007).

19 Egger HL, Angold A. Common emotional and behavioural disorders in preschool children: presentation, nosology and epidemiology. J Child Psychol Psychiatry 2006;47:313-37.

20 Fergusson DM, Horwood U, Ridder EM. Show me the child at 7: the consequences of conduct problems in childhood for psychosocial functioning in adulthood. J Child Psychol Psychiatry 2005:46:837-49.

21 Bramble D. Annotation: the use of psychotropic medications in Britain: a British view. J Child Psychol Psychiatry 2003:44:169-79.

22 Gradwell R, Taylor A. Audit of risperidone prescribing in children and young people aged 16 years and under. Arch Dis Child 2006;91/Suppl 1):A41.

23 Kutcher S, Aman M, Brooks SJ, et al. International consensus statement on attention-deficit/ hyperactivity disorder (ADHD) and disruptive behavioural disorders (DBDs): clinical implications and treatment practice suggestions. Eur Neuropsychopharmacol 2004; 14: 1 1-28.

24 Connor DS, Glatt SJ, Lopez ID, et al. Psychopharmacology and aggression. I: A metaanalysis of stimulant effects on overt/covert aggression-related behaviours in ADHD, J Am Acad Child Adolesc Psychiatry 2002:41:253-61.

25 Hazell PL, Stuart JE. A randomized control trial of clonidine added to psycho-stimulant medication for hyperactive and aggressive children. J Am Acad Child Adolesc Psychiatry 2003;42:886-94.

26 Schur SB, Sikich L, Findling RL, et al. Treatment recommendations for the use of antipsychotics for aggressive youth (TRAAY). Part 1: A review. J Am Acad Child Adolesc Psychiatry 2002;42:132-44.

27 Department of Health. Promoting the mental health and psychological well-being of children and young people: report on the implementation of Standard 9 of the National Service Framework for Children, Young People and Maternity Services. London: Department of Health, 2006. 